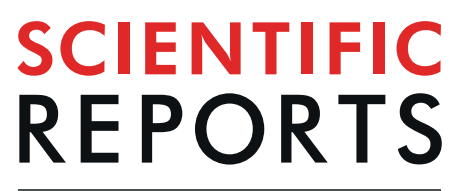

natureresearch

Received: 25 March 2018

Accepted: 7 August 2019

Published online: 22 August 2019

\title{
Real-time imaging of photosynthetic oxygen evolution from spinach using LSI-based biosensor
}

\author{
Shigenobu Kasai ${ }^{1,2}{ }^{2}$, Yamato Sugiura ${ }^{1}$, Ankush Prasad ${ }^{3}$, KumiY. Inoue ${ }^{4}$, Teruya Sato ${ }^{1}$, \\ Tomohiro Honmo ${ }^{1}$, Aditya Kumar ${ }^{3}$, Pavel Pospí̌ili ${ }^{3}$, Kosuke Ino ${ }^{5}$, Yuka Hashi', \\ Yoko Furubayashi ${ }^{4}$, Masahki Matsudaira ${ }^{4}$, Atsushi Suda ${ }^{6}$, Ryota Kunikata ${ }^{6}$ \& \\ Tomokazu Matsue ${ }^{4,5}$
}

The light-driven splitting of water to oxygen $\left(\mathrm{O}_{2}\right)$ is catalyzed by a protein-bound tetra-manganese penta-oxygen calcium $\left(\mathrm{Mn}_{4} \mathrm{O}_{5} \mathrm{Ca}\right.$ ) cluster in Photosystem II. In the current study, we used a largescale integration (LSI)-based amperometric sensor array system, designated Bio-LSI, to perform two-dimensional imaging of light-induced $\mathrm{O}_{2}$ evolution from spinach leaves. The employed BioLSI chip consists of 400 sensor electrodes with a pitch of $250 \mu \mathrm{m}$ for fast electrochemical imaging. Spinach leaves were illuminated to varying intensities of white light $(400-700 \mathrm{~nm})$ which induced oxygen evolution and subsequent electrochemical images were collected using the Bio-LSI chip. Bio-LSI images clearly showed the dose-dependent effects of the light-induced oxygen release from spinach leaves which was then significantly suppressed in the presence of urea-type herbicide 3-(3,4-dichlorophenyl)-1,1-dimethylurea (DCMU). Our results clearly suggest that light-induced oxygen evolution can be monitored using the chip and suggesting that the Bio-LSI is a promising tool for real-time imaging. To the best of our knowledge, this report is the first to describe electrochemical imaging of light-induced $\mathrm{O}_{2}$ evolution using LSI-based amperometric sensors in plants.

Molecular oxygen $\left(\mathrm{O}_{2}\right)$ during the evolution is known to be introduced into the environment about $\sim 2.7$ billion years ago by the $\mathrm{O}_{2}$ evolving photosynthetic organisms ${ }^{1}$. In the photosynthetic organisms, chloroplast and mitochondria are the main organelles responsible for the production and consumption of $\mathrm{O}_{2}$, respectively ${ }^{2}$. Photosynthetic water oxidation to $\mathrm{O}_{2}$ is catalyzed by a tetra-manganese penta-oxygen calcium $\left(\mathrm{Mn}_{4} \mathrm{O}_{5} \mathrm{Ca}\right)$ cluster bound to the proteins of photosystem II (PSII) $)^{3-6}$. Several techniques have been used in the past to measure $\mathrm{O}_{2}$ evolution in plants ${ }^{7-11}$. Each method utilized for detection and estimation of $\mathrm{O}_{2}$ has some strengths and limitations. The electrochemical method has been used for detection of $\mathrm{O}_{2}$ concentration including the Clark-type and Joloit-type electrode ${ }^{12-14}$. Quenching based $\mathrm{O}_{2}$ sensors which are prepared by embedding the fluorophore in $\mathrm{O}_{2}$ permeable polymer matrix [Polyvinyl chloride (PVC) or silicone] have an advantage as they are generally usable in both liquid and gaseous phase ${ }^{9}$. As quenching-based oxygen sensors, $\mathrm{Ru}(\mathrm{II}) \alpha$-diimine complexes (15) and $\mathrm{Pt}(\mathrm{II}) / \mathrm{Pd}(\mathrm{II})$ porphyrin systems are among the most studied ${ }^{15-18}$. In addition to the above techniques, EPR oximetry, mass spectrometry, photoacoustic spectroscopy cannot be easily used in plant systems and therefore not widely employed in photosynthetic research. The electrochemical technique has an advantage of direct detection of $\mathrm{O}_{2}$ without labels and additional reagents. As an example, electrochemical $\mathrm{O}_{2}$ analyzers based on the reduction of $\mathrm{O}_{2}$ at a negatively polarized platinum (Pt; electrode diameter: $25-75 \mu \mathrm{m}$ ) electrode have been demonstrated ${ }^{19,20}$. An ultra-microelectrode (diameter: $1.5 \mu \mathrm{m}$ ) was also introduced and inserted into a single

\footnotetext{
${ }^{1}$ Graduate Department of Environmental Information Engineering, Tohoku Institute of Technology, Sendai, Japan. ${ }^{2}$ Biomedical Engineering Research Center, Tohoku Institute of Technology, Sendai, Japan. ${ }^{3}$ Department of Biophysics, Centre of the Region Haná for Biotechnological and Agricultural Research, Faculty of Science, Palacký University, Olomouc, Czech Republic. ${ }^{4}$ Graduate School of Environmental Studies, Tohoku University, Sendai, Japan. ${ }^{5}$ Graduate School of Engineering, Tohoku University, Aoba-ku, Sendai, Japan. ${ }^{6} J a p a n$ Aviation Electronics Industry, Limited, Tokyo, Japan. Correspondence and requests for materials should be addressed to S.K. (email: kasai@ tohtech.ac.jp) or A.P. (email: prasad.ankush@gmail.com)
} 

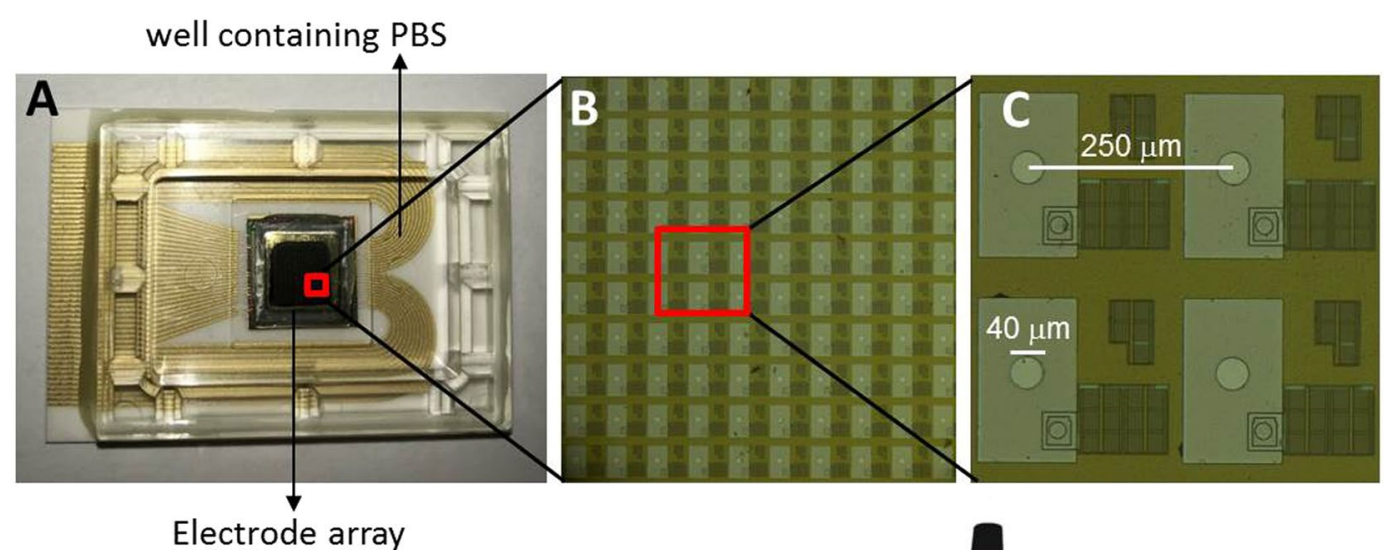

Electrode array

D

E
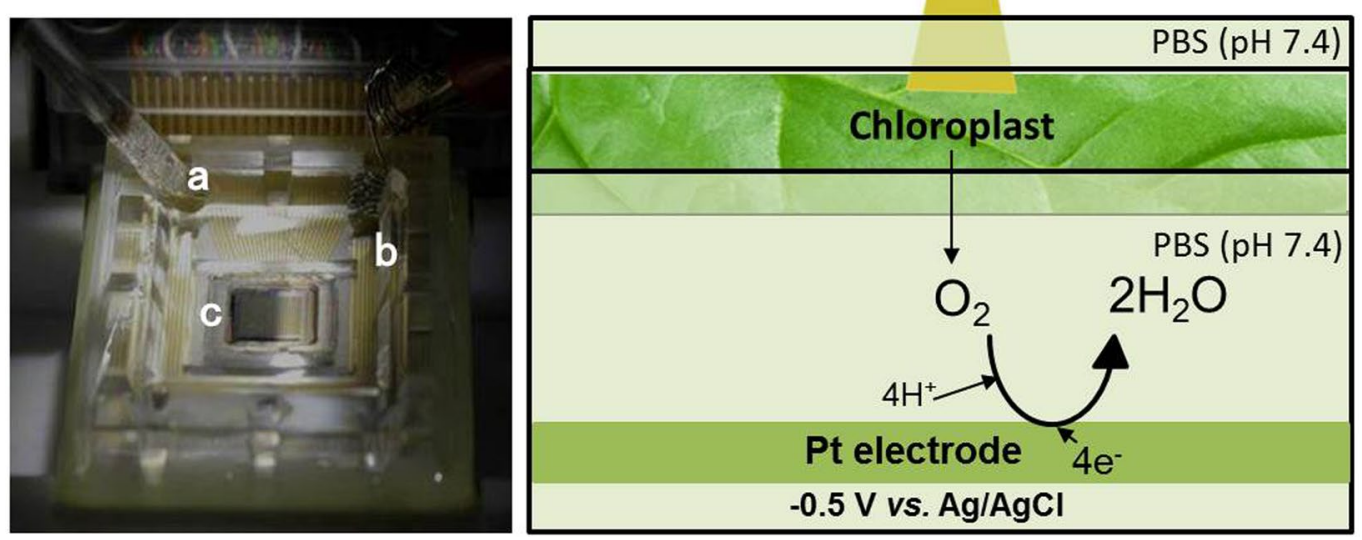

Figure 1. The photograph of the Bio-LSI chip (A), magnified images of Bio-LSI chip showing sensor points (B) and sensor electrodes (C). The diameter of each electrode is $40 \mu \mathrm{m}$ and the distances between the electrodes are $250 \mu \mathrm{m}$. The measurement setup of electrode cell (D) with an RE (a) and a CE (b) placed in the same well as WEs (c). Schematic illustration of the measurement system (E) for the photosynthetic activity in plant tissues by detecting the $\mathrm{O}_{2}$ as reduction current on the WEs of Bio-LSI.

cell to determine intercellular reduction current for $\mathrm{O}_{2}{ }^{19,20}$. More recently, scanning electrochemical microscopy (SECM) has been used for the imaging of $\mathrm{O}_{2}$ evolution during photosynthesis around single living cells ${ }^{21}$. SECM provides in addition to topographic information's, more detailed information (temporal) on the cellular activity such as respiration etc. ${ }^{22-24}$.

In the present study, we used our recently developed LSI-based amperometric sensor array system referred to as Bio-LSI ${ }^{25,26}$ for two-dimensional imaging of light-induced $\mathrm{O}_{2}$ evolution from spinach leaves. The Bio-LSI comprised of a $10.4 \mathrm{~mm} \times 10.4 \mathrm{~mm}$ complementary metal-oxide semiconductor (CMOS) sensor chip with $20 \times 20$ unit cells, an external circuit box, a control unit for data acquisition, and a DC power box. Each unit cell of the chip consists of an operational amplifier with a switched-capacitor type I-V converter for in-pixel signal amplification, which realizes a fast acquisition of electrochemical images with high sensitivity. On the Bio-LSI chip, the spinach leaves were illuminated with white light to induce $\mathrm{O}_{2}$ evolution and simultaneous imaging was performed. To the best of our knowledge, this is the first study to describe real-time electrochemical imaging of light-induced oxygen release from a photosynthetic organism using LSI-based amperometric sensors.

\section{Material and Methods}

Sample and chemical reagents. Spinach (Spinacia oleracea) leaves were purchased from the local market and washed twice with deionized water. The leaves were stored in dark for two hours before measurement to avoid any kind of light interference during the measurement. For each measurement, a fresh spinach leaf of the approximately same age and size were chosen. The experiments were performed under the dark condition and at room temperature $\left(25^{\circ} \mathrm{C}\right)$. 3-(3, 4-dichlorophenyl)-1, 1-dimethylurea (DCMU) $\geq 98 \%$ was purchased from Wako Pure Chemicals Industries, Ltd. (Osaka, Japan).

Fabrication of Bio-LSI chip and measurement setup. The detailed fabrication process for the sensor chip has been described in our previous study ${ }^{27}$. In summary, it consists of 400 working electrodes arranged in an array of $20 \times 20$ electrodes as represented in Fig. 1(A-C). The overall measurement setup consists of a reference 


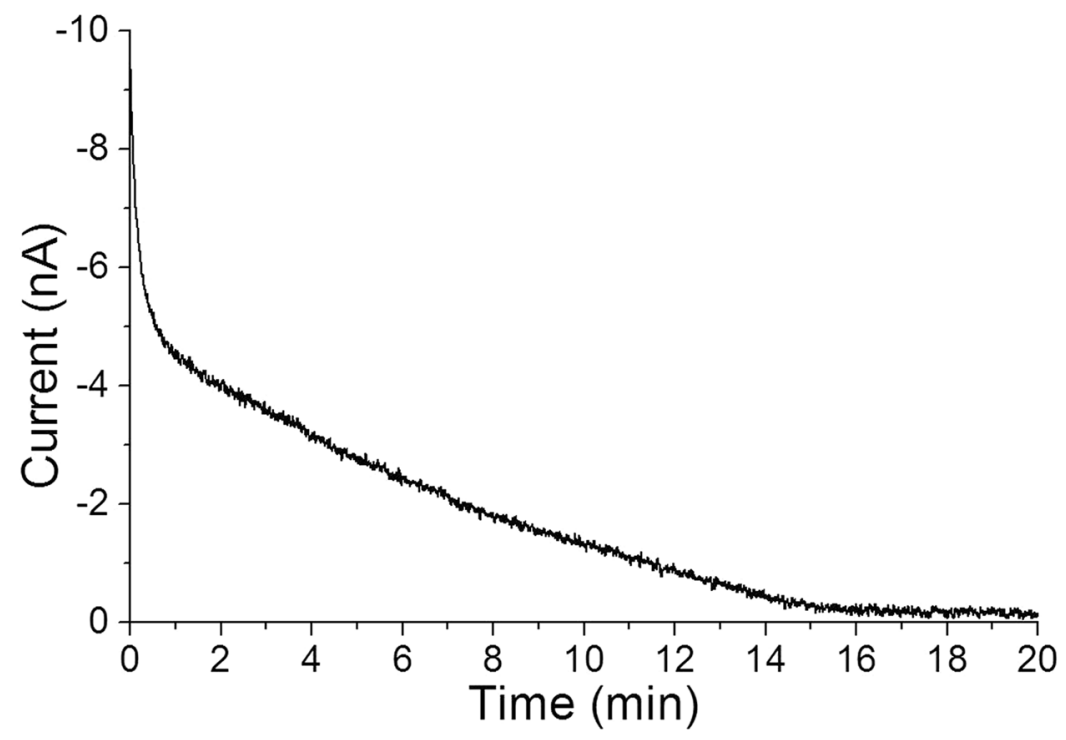

Figure 2. Time course of the deoxygenation. The DO reduction current on a WE of a Bio-LSI chip was monitored during the pretreatment for deoxygenation of the well. A voltage of $-0.5 \mathrm{~V} v \mathrm{vs} \mathrm{Ag} / \mathrm{AgCl}$ was applied to $400 \mathrm{WEs}$ for $20 \mathrm{~min}$.

electrode (RE): $\mathrm{Ag} / \mathrm{AgCl}$; a counter electrode (CE): a platinum (Pt) wire and 400 working electrodes (WEs) on the Bio-LSI chip (Fig. 1D). The WE is a Pt electrode each with a diameter of $40 \mu \mathrm{m}$. The RE and CE were inserted from the top as represented in Fig. 1D while the leaf excised sample rests above the WEs. The distance between the leaf sample and the Bio-LSI chip was less than $\sim 1 \mathrm{~mm}$ due to the uneven surface area of the leaf. Some parts of the sample contacted to the sensing area. The ventral side of the leaf known to possess the stomata was placed on the electrode part for the purpose of acquiring the image. In the well positioned above the Bio-LSI chip, a phosphate buffer saline (PBS) $(40 \mathrm{mM})$ at $\mathrm{pH} 7.4$ was accommodated. The setup was established precisely using a stereoscopic microscope (Leica S8 APO).

Deoxygenation. To avoid any interference of dissolved oxygen (DO) in the system containing PBS (without leaves), we conducted deoxygenation in the measurement well by applying a potential of $-0.5 \mathrm{~V} v s \mathrm{Ag} / \mathrm{AgCl}$ to the WEs before measurements. Reaction on the Pt WEs during the deoxygenation was as follows.

$$
\mathrm{O}_{2}+4 \mathrm{H}^{+}+4 \mathrm{e}^{-} \rightarrow 2 \mathrm{H}_{2} \mathrm{O}
$$

The monitored current generated by the above reaction was gradually decreased from $-8 \mathrm{nA}$ to $\sim-0.2 \mathrm{nA}$ in the time span of $20 \mathrm{~min}$ (Fig. 2). The remaining current was derived from diffusion of fresh oxygen from the atmosphere. From this result, we consider that the deoxygenation was completed in about $20 \mathrm{~min}$.

Real-time imaging and current monitoring of oxygen evolution during photosynthesis using Bio-LSI. For the real-time imaging of $\mathrm{O}_{2}$ evolution during the light-induced photosynthetic process, PBS was filled in the well containing WEs (Fig. 1A). Prior to this, spinach leaf in the dimension $5 \mathrm{~mm} \times 2 \mathrm{~mm}$ was positioned on the WEs. A potential of $-0.5 \mathrm{~V} v s$. $\mathrm{Ag} / \mathrm{AgCl}$ was applied to the WEs until the reduction current of DO was stabilized to $\sim 0 \mathrm{nA}$. This was followed by two-dimensional imaging of $\mathrm{O}_{2}$ evolution from the spinach leaf by continuous application of $-0.5 \mathrm{~V} v s$. $\mathrm{Ag} / \mathrm{AgCl}$ to the WEs. The light exposure was achieved using a KL300 LED light source $(\lambda=400-800 \mathrm{~nm})$ connected with a light guide (Schott AG, Hattenbergstrasse 10, Mainz, Germany) with light intensities of $0 \mathrm{klx}, 3 \mathrm{klx}\left(40 \mu \mathrm{mol}\right.$ photons s $\left.\mathrm{m}^{-1}\right), 20 \mathrm{klx}\left(260 \mu \mathrm{mol}\right.$ photons s $\left.\mathrm{m}^{-1} \mathrm{~m}^{-2}\right)$ and $30 \mathrm{klx}$ $\left(400 \mu \mathrm{mol}\right.$ photons $\left.\mathrm{s}^{-1} \mathrm{~m}^{-2}\right)$. The intensities of light in the current study were chosen based on the data provided by the Osaka Science Museum, Osaka, Japan. The light intensities used in our study reflect the situation close to field conditions. As a negative control, we performed the same experiments in the absence of spinach leaf. For time course monitoring of the reduction current, current data from a single randomly selected electrode (indicated by a red open square) from the electrode sensor array system was chosen. We also examined the effect of a photosynthetic inhibitor on the oxygen evolution by addition of DCMU prior to start (Supplementary Data 1) and during measurements. All images presented in the manuscript are representative figures of at least 3 measurements.

\section{Results}

Real-time imaging of oxygen evolution during photosynthesis with different intensities of illumination. Real-time imaging of $\mathrm{O}_{2}$ evolution from a spinach leaf was performed under the different illumination intensities $\left(3 \mathrm{klx}, 20 \mathrm{klx}\right.$, and $30 \mathrm{klx}$ ). The spatial distribution of $\mathrm{O}_{2}$ was monitored as $\mathrm{O}_{2}$ reduction current measured with the Bio-LSI chip applied with $-0.5 \mathrm{~V} v s$. Ag/AgCl. Figure $3 \mathrm{~A}$ shows the photograph of $400 \mathrm{WEs}$ on a Bio-LSI and Fig. 3B shows a two-dimensional image of $\mathrm{O}_{2}$ reduction current measured without any illumination 

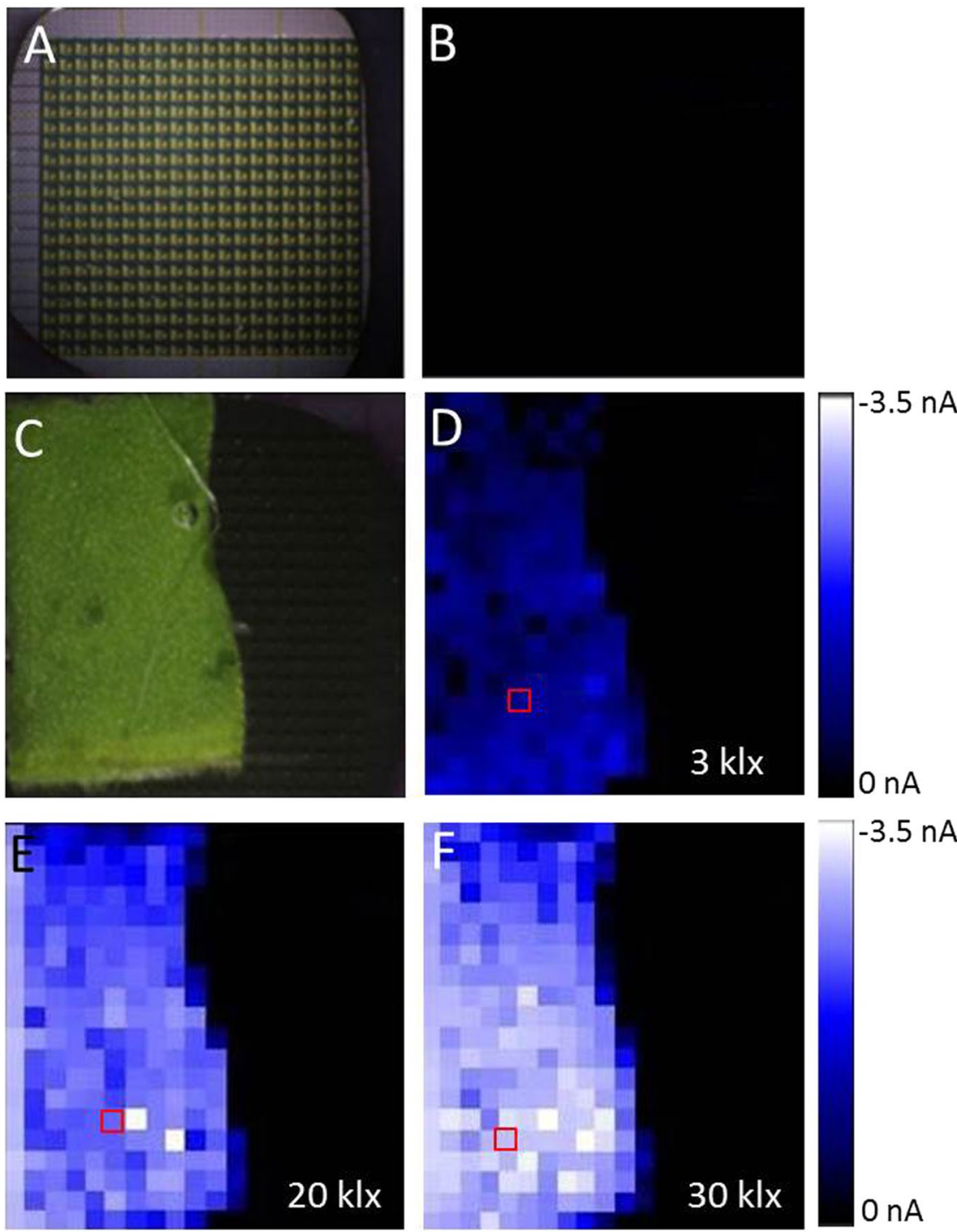

Figure 3. Photograph of 400 WEs on a Bio-LSI (A) and an image of $\mathrm{O}_{2}$ distribution based on the reduction current of $\mathrm{O}_{2}$ measured in the absence of spinach leaf (B). A photograph showing the arrangement of spinach leaf on the electrode surface $(\mathbf{C})$ and images of $\mathrm{O}_{2}$ evolution after $5 \mathrm{~min}$ of light exposure from the spinach illuminated with $3 \mathrm{klx}(\mathbf{D}), 20 \mathrm{klx}(\mathbf{E})$ and $30 \mathrm{klx}(\mathbf{F})$.

in the absence of spinach leaf. Figure 3C shows the arrangement of spinach leaf on the electrode surface of the Bio-LSI chip during the measurements. Figures 3D-F are the two-dimensional images for $\mathrm{O}_{2}$ reduction current measured at the illumination of $3 \mathrm{klx}, 20 \mathrm{klx}$ and $30 \mathrm{klx}$, respectively. Supplementary Data 2 shows additional set of data on two-dimensional imaging of $\mathrm{O}_{2}$ reduction current measured at the illumination of $3 \mathrm{klx}, 10 \mathrm{klx}, 20$ $\mathrm{klx}$ and $30 \mathrm{klx}$. The electrodes close with the leaf surface showed a change in reduction current in the range of $-0.5 \mathrm{nA}$ to $-3.5 \mathrm{nA}$, while the electrodes far from the leaf did not show any significant changes in the reduction current. With the increase of light intensities, the change in $\mathrm{O}_{2}$ reduction current was increased. Supplementary Data 3 (video 1) shows the change in $\mathrm{O}_{2}$ reduction current in real-time during the turning on/off the light at 30 $\mathrm{klx}$. As a control experiment, real-time imaging of $\mathrm{O}_{2}$ evolution from the dorsal side of the spinach leaf bearing no stomata was measured (data not shown). No significant change in $\mathrm{O}_{2}$ reduction current was observed which is believed to be due to non-feasible long-distance diffusion of oxygen.

Time course of oxygen evolution during photosynthesis at different intensities of illumination. The time course of $\mathrm{O}_{2}$ evolution from spinach leaves during illumination with different intensities was compared. The changes in $\mathrm{O}_{2}$ reduction current monitored at a single electrode of the electrode array system are shown in Fig. 4. Exposure to white light at $3 \mathrm{klx}$ leads to change in $\mathrm{O}_{2}$ reduction current by $-1 \mathrm{nA}$ which was significantly increased to $-2.3 \mathrm{nA}$ and $-3.0 \mathrm{nA}$ with exposure to light intensities of $20 \mathrm{klx}$ and $30 \mathrm{klx}$, respectively. The $\mathrm{O}_{2}$ evolution depending on the illumination intensity was clearly monitored by the Bio-LSI system. With the turning off the light, the oxygen reduction current showed a sharp decrease to a value equivalent to the value observed during 


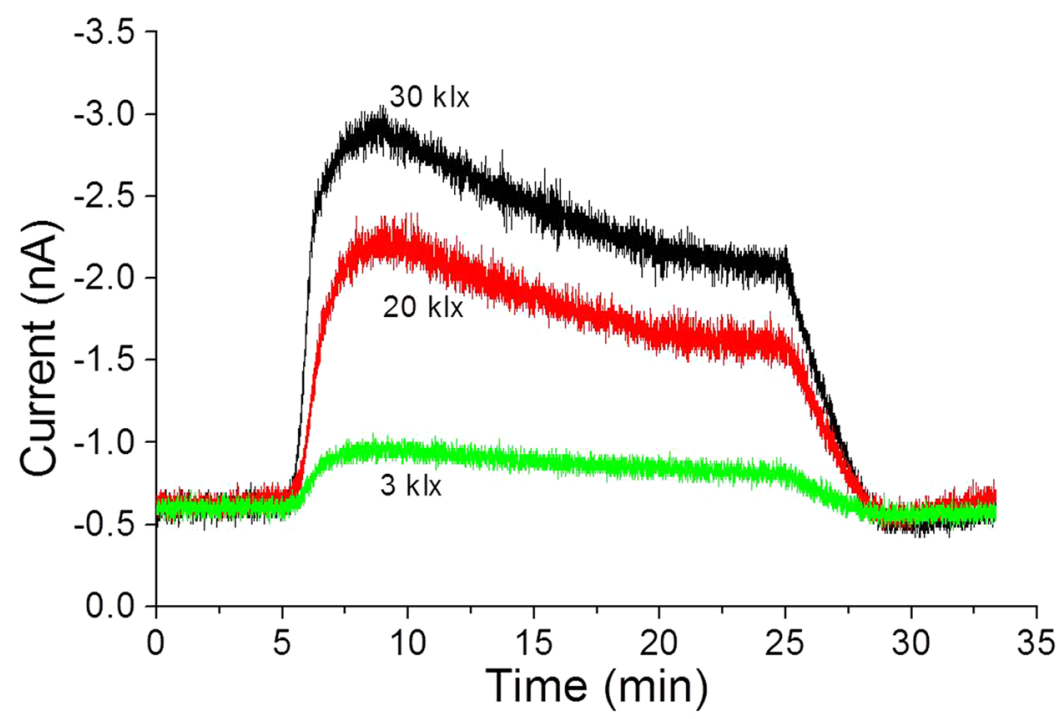

Figure 4. Changes in $\mathrm{O}_{2}$ reduction current of a single randomly selected electrode (indicated by a red open square in Fig. 3) measured with a spinach leaves illuminated by $3 \mathrm{klx}$ (green trace), $20 \mathrm{klx}$ (red trace) and $30 \mathrm{klx}$ (black trace).

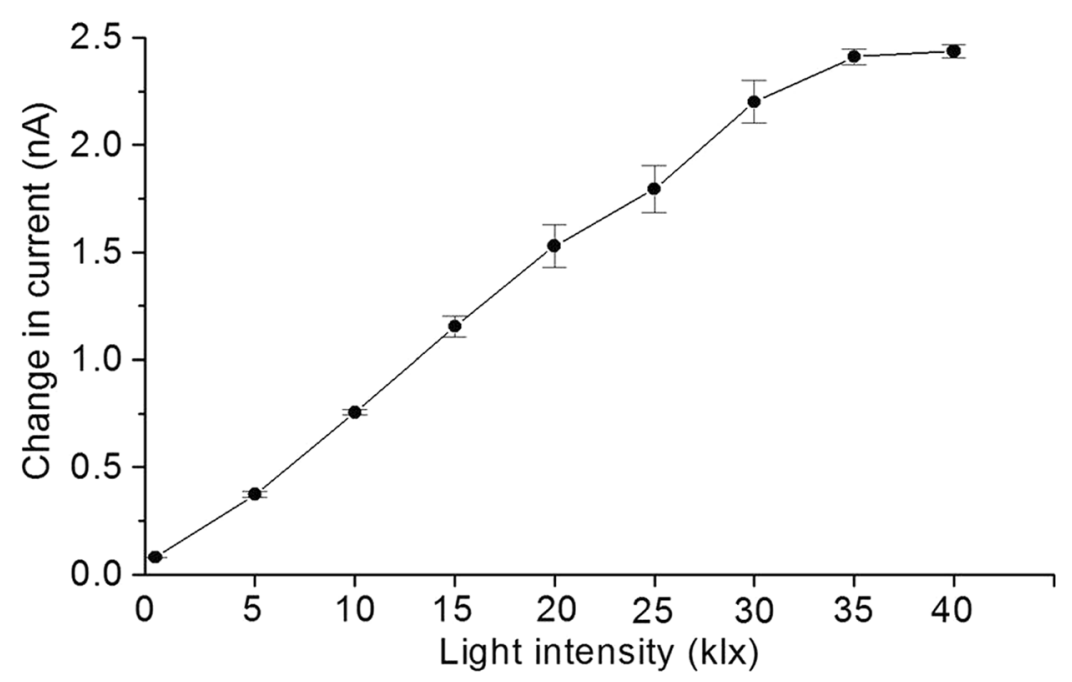

Figure 5. Change in $\mathrm{O}_{2}$ reduction current $(\Delta I)$ showing the difference between the background current and value of oxygen reduction current (moving average) measured using Bio-LSI based on the experimental conditions described in Fig. 4. The change in $\mathrm{O}_{2}$ reduction current $(\Delta I$, in $\mathrm{nA}$ ) was measured during the illumination at intensity range of $0-40 \mathrm{klx}$.

\begin{tabular}{|c|c|c|c|c|c|c|c|c|c|}
\hline & $\Delta \mathrm{I}_{1(\mathrm{nA})}$ & $\Delta \mathrm{T}_{1 \text { (sec) }}$ & $\mathrm{V}_{1(\mathrm{nmol} / \mathrm{sec})}$ & $\Delta \mathrm{I}_{2(\mathrm{nA})}$ & $\Delta \mathrm{T}_{2(\mathrm{sec})}$ & $\mathrm{V}_{2(\mathrm{nmol} / \mathrm{sec})}$ & $\Delta \mathrm{I}_{3(\mathrm{nA})}$ & $\Delta \mathrm{T}_{3(\mathrm{sec})}$ & $\mathbf{V}_{3(\mathrm{nmol} / \mathrm{sec})}$ \\
\hline $3 \mathrm{klx}$ & 0.3 & 200 & 47 & 0.1 & 880 & 4 & 0.2 & 240 & 26 \\
\hline $20 \mathrm{klx}$ & 1.6 & 240 & 211 & 0.6 & 840 & 23 & 1.0 & 240 & 132 \\
\hline $30 \mathrm{klx}$ & 2.3 & 240 & 303 & 0.8 & 840 & 30 & 1.5 & 240 & 198 \\
\hline
\end{tabular}

Table 1. Oxygen evolution (in nmol) calculated using standard bulk dissolved oxygen concentration measured in the case of a Pt electrode (diameter $40 \mu \mathrm{m}$ ) having a measurement solution (PBS) and temperature of $25^{\circ} \mathrm{C}$. The oxygen evolution ( $\mathrm{V}$, in $\mathrm{nmol}$ ) was calculated during the illumination at the intensity range of $3 \mathrm{klx}, 20 \mathrm{klx}$ and $30 \mathrm{klx}$.

first $5 \mathrm{~min}$ (no illumination). It can also be seen that the reduction current value began to gradually decrease after 5 min of illumination (Fig. 4, red and black trace). This may be because of consumption of $\mathrm{O}_{2}$ due to continuous application of a potential to the electrode, $\mathrm{O}_{2}$ reduction by PSII and limited $\mathrm{O}_{2}$ production by the plant tissue. 


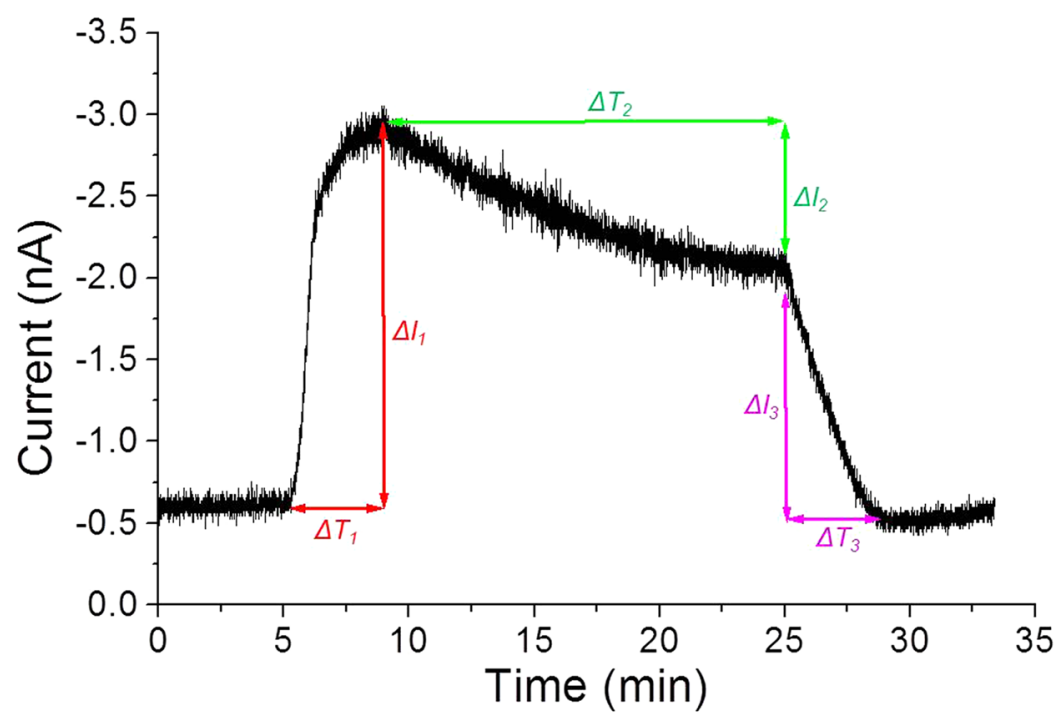

Figure 6. Details showing parameters utilized for calculation of oxygen evolution. Changes in $\mathrm{O}_{2}$ reduction current of a single randomly selected electrode (indicated by a red open square in Fig. 3) measured with spinach leaves illuminated at $30 \mathrm{klx}$. $\mathrm{V}, \Delta I$ and $\Delta T$ represents the concentration of evolved $\mathrm{O}_{2}$, change in $\mathrm{O}_{2}$ reduction current and time duration, respectively. The parameters were considered for calculations of oxygen evolution as presented in Table 1.

For a further understanding of the behavior of $\mathrm{O}_{2}$ evolution during illumination, the change in $\mathrm{O}_{2}$ reduction current $(\Delta I)$ from the current just before the turning on of the light at different period of illumination were plotted as averages of 3 randomly selected electrodes under the leaf with error bars indicating standard deviations. Figure 5 shows the $\Delta I$ at light intensities in the range of $0-40 \mathrm{klx}$. The $\mathrm{O}_{2}$ evolution reflected by a change in reduction current was almost proportional to light intensity up to $30 \mathrm{klx}$; however, the response was saturated when the light intensity exceeded $35 \mathrm{klx}$. The saturation intensity and oxygen-evolution rate are important factors describing the photosynthetic capability of plant leaves. The above results indicate that amperometric measurement using Bio-LSI is applicable to screen the photosynthetic capability of the leaves including the oxygen constraining process of carbon fixation.

In order to estimate the molecules of $\mathrm{O}_{2}$ evolved, the background reduction current value of the measurement solution and the DO concentration (estimated to be about $253 \mu \mathrm{M}$ in the case of an electrode having a measurement solution temperature of $25^{\circ} \mathrm{C}$ and a radius of $40 \mu \mathrm{m}$ ) were taken into account. The oxygen concentration was recalculated and has been presented in Table 1 based on parameters shows in Fig. 6.

Real-time imaging of oxygen reduction current with photosynthetic inhibition. Real-time imaging of $\mathrm{O}_{2}$ reduction current was performed in the presence of photosynthetic inhibitor of electron transport in PSII DCMU $(5 \mu \mathrm{M})$ to confirm the origin of the reduction current. Figure 7A shows the arrangement of spinach leaf on the Bio-LSI chip (a), an image of $\mathrm{O}_{2}$ reduction current before illumination (b) and an image during illumination $(30 \mathrm{klx})(\mathrm{c})$. To test the effect of photosynthetic inhibitor, DCMU was exogenously added during the illumination (d) and subsequent images were taken after every $3 \mathrm{~min}$ for a time span of $15 \mathrm{~min}$ (e-i). At the initial $5 \mathrm{~min}$ of DCMU addition, partial inhibition of oxygen evolution was observed and then, the inhibition was increased with time leading to complete inhibition after $15 \mathrm{~min}$ (i). Figure 7B shows the time course of the $\mathrm{O}_{2}$ reduction current changes on one electrode [indicated by a red open square in Fig. 7A(c)]. In addition to the above measurement, light-induced $\mathrm{O}_{2}$ evolution was also tested after the suppression by DCMU (Fig. 8). Figure 8A shows the arrangement of spinach leaf on the Bio-LSI chip (a), an image of $\mathrm{O}_{2}$ reduction current without illumination (b), and during illumination ( $30 \mathrm{klx})(\mathrm{c})$. After a suppression in $\mathrm{O}_{2}$ evolution by addition of $5 \mu \mathrm{M}$ DCMU, illumination was performed again, and subsequent images were taken every $2 \mathrm{~min}$ (e-i). Only a slight increase in oxygen reduction current was observed after the illumination which was found to rapidly decrease within 2 min. Figure $8 \mathrm{~B}$ shows the changes in $\mathrm{O}_{2}$ reduction current showing similar effects. With the first turning on of light illumination at $5 \mathrm{~min}$ in the absence of DCMU, the $\mathrm{O}_{2}$ reduction current increased to reach to $-2.5 \mathrm{nA}$. With the turning off the light, the current decreased to $-0.5 \mathrm{nA}$ within $5 \mathrm{~min}$. With the addition of DCMU at this point and at a lapse of $5 \mathrm{~min}$, the light source was turned on again. The small increase of the $\mathrm{O}_{2}$ reduction current was observed but the peak of the current was reduced by about $1 / 2$ and quickly decreased due to the inhibitory effect of DCMU on the $\mathrm{O}_{2}$ evolution activity of the photosynthesis. These results indicate the potential of the Bio-LSI to be used for the monitoring the $\mathrm{O}_{2}$ evolution activity as well as the impact of the environmental stresses to the tissues. 
A
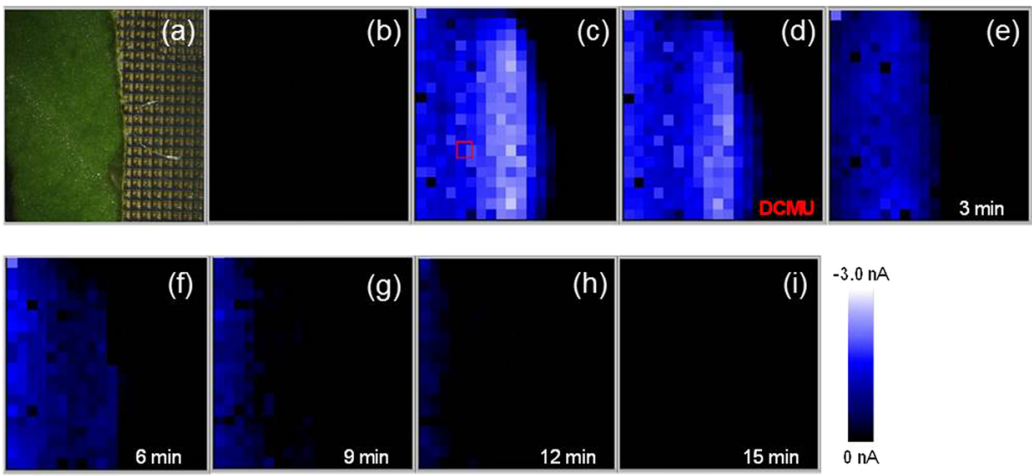

B

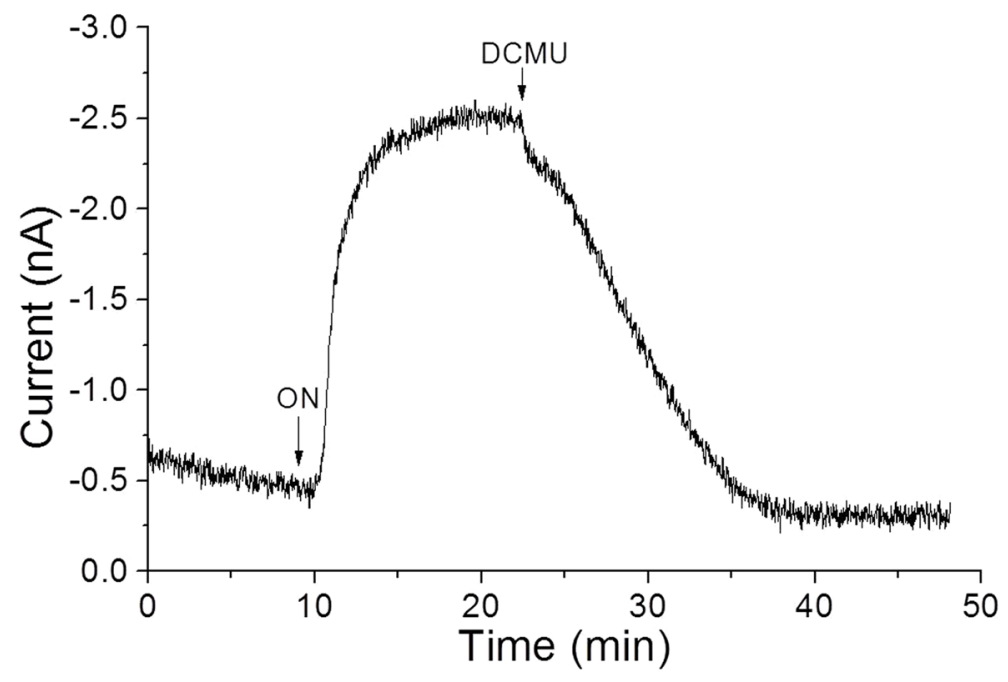

Figure 7. (A) Photograph showing the arrangement of spinach leaf on the Bio-LSI chip (a), real-time imaging of $\mathrm{O}_{2}$ reduction current without illumination (b) and with illumination at $30 \mathrm{klx}(\mathrm{c})$. DCMU $(5 \mu \mathrm{M})$ was added after $13 \mathrm{~min}$ from the start of illumination $(30 \mathrm{klx})$ and subsequent images were obtained at $0 \mathrm{~min}(\mathrm{~d}), 3 \mathrm{~min}(\mathrm{e})$, $6 \mathrm{~min}(\mathrm{f}), 9 \mathrm{~min}(\mathrm{~g}), 12 \mathrm{~min}(\mathrm{~h})$ and $15 \mathrm{~min}$ (i). (B) The change in reduction current on an electrode indicated by a red open square in Fig. $7 \mathrm{~A}(\mathrm{c})$. The arrow indicates the time of turning on the light (at $10 \mathrm{~min})$ and subsequent addition of DCMU (at $23 \mathrm{~min}$ ).

\section{Discussion}

In this study, we demonstrated real-time monitoring of $\mathrm{O}_{2}$ evolution from a spinach leaf with light illumination by a change in $\mathrm{O}_{2}$ reduction current using an LSI-based amperometric sensor array system called Bio-LSI. With the increase of the light intensities from $0 \mathrm{klx}$ to $30 \mathrm{klx}$, the reduction current reflecting oxygen evolution from the leaf was increased almost proportional to light intensity while the electrodes far from the leaf did not show any significant changes in the reduction current (Figs 3, 7A, 8A). With the turning off the light, the oxygen reduction current showed a sharp decrease to a value equivalent to first $5 \mathrm{~min}$. In addition, we observed a decrease of $\mathrm{O}_{2}$ reduction current with applying $5 \mu \mathrm{M}$ of photosynthetic inhibitor DCMU to the illuminated leaf, showing that we detected the photosynthetic activity of plant tissue (Fig. 7B). This technique can be broadly applied to investigate the effect of chemical and physical stimulation on the photosynthetic organism including the impact of the environmental stresses to the plant tissues.

Several conventional methods including polarography, EPR oximetry, mass spectrometry, photoacoustic spectroscopy and galvanic sensors have been used to measure photosynthetic oxygen evolution over the past years; however, most of them can only offer mean values which lack spatial resolution and are therefore blind to any compartmentation within the sample ${ }^{28}$. The imaging methods for oxygen consumption, oxygen evolution and subsequent reactive oxygen species characterization which were used during the past decades in photosynthetic research were mainly the fluorescence-based measurements. Fluorescence measurements offer wide applicability; however undesired fluctuation by quenching/emission from other materials, shielding due to the solution (turbidity of the medium) and need for probe labelling has to be considered. As far as probes labelling is concerned, there are several issues related which includes but not limited to fluorescent probes cross-reactivity, the existence of endogenous fluorochromes, excitation and emission wavelengths overlap, probe uptake, toxicity-either of the fluorescent compounds and/or solvent etc. In the current study, the Bio-LSI chip has been presented for the 
A
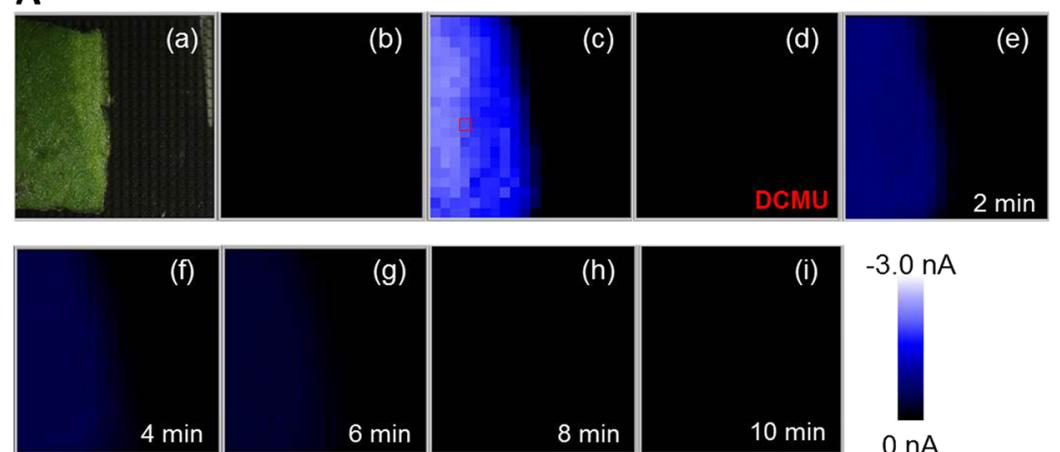

$-3.0 \mathrm{nA}$

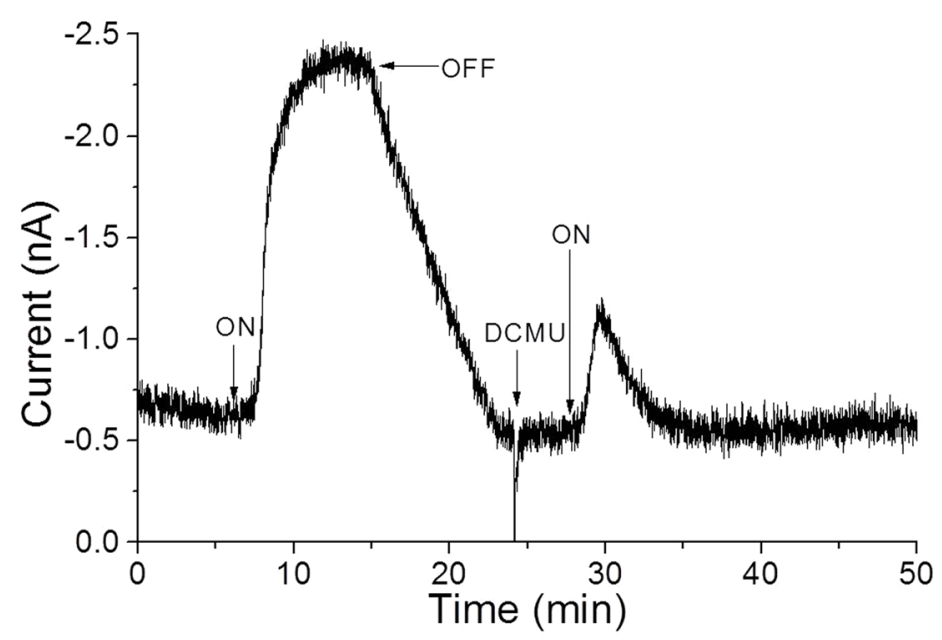

Figure 8. (A) Photograph showing the arrangement of spinach leaf on the Bio-LSI chip (a), real-time imaging of $\mathrm{O}_{2}$ reduction current without (b) and with illumination at $30 \mathrm{klx}$ (c). The illumination was turned off $10 \mathrm{~min}$ after the start of illumination and DCMU $(5 \mu \mathrm{M})$ was added $10 \mathrm{~min}$ after turning off the light. Then, the illumination was turned on again after the addition of DCMU and subsequent images were taken at $0 \mathrm{~min}(\mathrm{~d})$, $2 \mathrm{~min}(\mathrm{e}), 4 \mathrm{~min}$ (f), $6 \mathrm{~min}(\mathrm{~g}), 8 \mathrm{~min}(\mathrm{~h}), 10 \mathrm{~min}$ (i) after turning on the light (at $28 \mathrm{~min}$ ). (B) The change in reduction current measured on a single randomly selected electrode (indicated by a red open square in Fig. 8C).

real-time imaging of photosynthetic oxygen evolution from spinach. Through the modification of electrodes, the use of the device can be extended for detection of other chemical species/reactive species. Bio-LSI chip has an advantage considering the simplicity and easy handling of the measurement setup with no interferences from exogenous probes/chemicals and wider applicability. It is possible to detect oxygen production rate with higher sensitivity [in the range of $\mathrm{nmol} / \mathrm{sec}$ ] and from larger surface area. Thus, it offers multi-point biosensing with higher sensitivity. The current system is non-invasive and future development w.r.t sensing points can enhance spatial and temporal resolution considerably. The Bio-LSI being equipped with CMOS sensor chip and operational amplifier within each unit cell not only makes it compactly designed and easy to handle but also offer in-pixel signal amplification, fast acquisition and high sensitivity which makes its a promising tool in photosynthetic research and more broadly in investigating different aspect in plant science research.

Some technical limitations are however associated with Bio-LSI especially in the context of temporal measurements. The data resulting from 400 electrodes at $100 \mathrm{~ms}$ interval will be enormous and thus choosing to follow 1 electrode/up to few electrodes for plotting the temporal distribution of changes in oxygen reduction current presented as Figs 4, 7B, 8B are more feasible. Spatial resolution can also be affected to some extent since the distance between the leaf sample and the Bio-LSI chip at different electrode positions can slightly vary due to the uneven surface area of the leaf or any other biological sample. Since some part of the sensing area can be closer than other (mostly in case of solid samples), the change of the oxygen concentration can be subject to some errors. Thus, the diffusion of oxygen in the medium has to be taken into account and should not be completely neglected. Although there is a short delay due to the diffusion of molecules from targets to sensors in electrochemical imaging, "real-time" is generally used". 


\section{References}

1. Crowe, S. A. et al. Atmospheric oxygenation three billion years ago. Nature 501, 535-+, https://doi.org/10.1038/nature12426 (2013).

2. Ligeza, A., Tikhonov, A. N. \& Subczynski, W. K. In situ measurements of oxygen production and consumption using paramagnetic fusinite particles injected into a bean leaf. Biochimica Et Biophysica Acta-Bioenergetics 1319, 133-137, https://doi.org/10.1016/ s0005-2728(96)00122-3 (1997).

3. Dau, H., Zaharieva, I. \& Haumann, M. Recent developments in research on water oxidation by photosystem II. Current Opinion in Chemical Biology 16, 3-10, https://doi.org/10.1016/j.cbpa.2012.02.011 (2012).

4. Yano, J. \& Yachandra, V. Mn4Ca Cluster in Photosynthesis: Where and How Water is Oxidized to Dioxygen. Chemical Reviews 114, 4175-4205, https://doi.org/10.1021/cr4004874 (2014).

5. Perez-Navarro, M., Neese, F., Lubitz, W., Pantazis, D. A. \& Cox, N. Recent developments in biological water oxidation. Current Opinion in Chemical Biology 31, 113-119, https://doi.org/10.1016/j.cbpa.2016.02.007 (2016).

6. Vinyard, D. J. \& Brudvig, G. W. In Annual Review of Physical Chemistry, Vol. 68 Annual Review of Physical Chemistry (eds Johnson, M. A. \& Martinez, T. J.) 101-116 (Annual Reviews, 2017).

7. Clark, L. C. Monitor and Control of Blood and Tissue Oxygen Tensions. Transactions American Society for Artificial Internal Organs 2, 41-\& (1956).

8. Delieu, T. \& Walker, D. A. Polarographic Measurement of Photosynthetic Oxygen Evolution By Leaf-Disks. New Phytologist 89, 165-178, https://doi.org/10.1111/j.1469-8137.1981.tb07480.x (1981).

9. Tyystjarvi, E., Karunen, J. \& Lemmetyinen, H. Measurement of photosynthetic oxygen evolution with a new type of oxygen sensor. Photosynthesis Research 56, 223-227, https://doi.org/10.1023/a:1005994311121 (1998).

10. Kendall, D. N. Berlman,Ib - Handbook of Fluorescence Spectra of Aromatic Molecules. Applied Spectroscopy 21, 203-\& (1967).

11. Wolfbeis, O. S. Fiber-optic chemical sensors and biosensors. Anal Chem 76, 3269-3283, https://doi.org/10.1021/ac040049d (2004).

12. Joliot, P. Oxygen evolution in algae illuminated with modulated light. In: Olson, J.M., Hind, G., Siegelman, H.W. (eds) Energy conversion by the photosynthetic apparatus. Upton, New York, 418-433 (1967).

13. Joliot, P. \& Joliot, A. A polarographic method for detection of oxygen production and reduction of Hill reagent by isolated chloroplasts. Biochimica et Biophysica Acta (BBA)-Bioenergetics 153(3), 625-634 (1968).

14. Clark, L.C. J.R., Wolf, R., Granger, D. \& Taylor, Z. Continuous recording of blood oxygen tensions by polarography. Journal of Applied Physiology 6, 189-193 (1953).

15. Demas, J. N. \& DeGraff, B. A. Applications of luminescent transition metal complexes to sensor technology and molecular probes. Journal of Chemical Education 74, 690-695, https://doi.org/10.1021/ed074p690 (1997).

16. Demas, J. N., DeGraff, B. A. \& Coleman, P. B. Oxygen sensors based on luminescence quenching. Analytical Chemistry 71, 793A-800A, https://doi.org/10.1021/ac9908546 (1999).

17. Kneas, K. A., Xu, W. Y., Demas, J. N. \& DeGraff, B. A. Oxygen sensors based on luminescence quenching: Interactions of tris(4,7diphenyl-1,10-phenanthroline)ruthenium(II) chloride and pyrene with polymer supports. Applied Spectroscopy 51, 1346-1351, https://doi.org/10.1366/0003702971942024 (1997).

18. Gouterman, M. Oxygen quenching of luminescence of pressure sensitive paint for wind tunnel research. Journal of Chemical Education 74, 697-702, https://doi.org/10.1021/ed074p697 (1997).

19. Matsue, T., Koike, S., Abe, T., Itabashi, T. \& Uchida, I. An Ultramicroelectrode For Determination of Intracellular Oxygen - LightIrradiation-Induced Change in Oxygen Concentration in an Algal Protoplast. Biochimica Et Biophysica Acta 1101, 69-72, https:// doi.org/10.1016/0167-4838(92)90468-s (1992).

20. Matsue, T., Koike, S. \& Uchida, I. Microamperometric Estimation of Photosynthesis Inhibition In A Single Algal Protoplast. Biochemical and Biophysical Research Communications 197, 1283-1287, https://doi.org/10.1006/bbrc.1993.2616 (1993).

21. Yasukawa, T., Kaya, T. \& Matsue, T. Dual imaging of topography and photosynthetic activity of a single protoplast by scanning electrochemical microscopy. Analytical Chemistry 71, 4637-4641, https://doi.org/10.1021/ac9903104 (1999).

22. Lee, C. M., Kwak, J. Y. \& Bard, A. J. Application of Scanning Electrochemical Microscopy To Biological Samples. Proceedings of the National Academy of Sciences of the United States of America 87, 1740-1743, https://doi.org/10.1073/pnas.87.5.1740 (1990).

23. Tsionsky, M., Cardon, Z. G., Bard, A. J. \& Jackson, R. B. Photosynthetic electron transport in single guard cells as measured by scanning electrochemical microscopy. Plant Physiology 113, 895-901, https://doi.org/10.1104/pp.113.3.895 (1997).

24. Yasukawa, T., Kaya, T. \& Matsue, T. Characterization and imaging of single cells with scanning electrochemical microscopy. Electroanalysis 12, 653-659, 10.1002/1521-4109(200005)12:9<653::aid-elan653>3.0.co;2-s (2000).

25. Inoue, K. Y. et al. LSI-based amperometric sensor for bio-imaging and multi-point biosensing. Lab on a Chip 12, 3481-3490, https:// doi.org/10.1039/c2lc40323d (2012).

26. Inoue, K. Y. et al. Advanced LSI-based amperometric sensor array with light-shielding structure for effective removal of photocurrent and mode selectable function for individual operation of 400 electrodes. Lab on a Chip 15, 848-856, https://doi. org/10.1039/c4lc01099j (2015).

27. Kanno, Y. et al. Electrochemicolor Imaging Using an LSI-Based Device for Multiplexed Cell Assays. Analytical Chemistry 89, 12778-12786, https://doi.org/10.1021/acs.analchem.7b03042 (2017).

28. Tschiersch, H., Liebsch, G., Borisjuk, L., Stangelmayer, A. \& Rolletschek, H. An imaging method for oxygen distribution, respiration and photosynthesis at a microscopic level of resolution. New Phytol 196, 926-936, https://doi.org/10.1111/j.1469-8137.2012.04295.x (2012).

29. Kasai, N., Shimada, A., Tobias, N., Torimitsu, K. Fabrication of an electrochemical sensor array for $2 \mathrm{D}$ H2O2 imaging. Electrochemistry 8, https://doi.org/10.5796/electrochemistry.74.628 (2006).

\section{Acknowledgements}

This work was financially supported by the MEXT-Supported Program for the Strategic Research Foundation at Private Universities, Japan; the European Regional Development Fund (ERDF) project "Plants as a tool for sustainable global development” (no. CZ.02.1.01/0.0/0.0/16_019/0000827) and IGA_PrF_2019_030 from Palacký University, Olomouc, Czech Republic.

\section{Author Contributions}

S.K. designed the study and wrote the initial draft of the manuscript. Y.S. performed the experiment. A.P. contributed in analysis, interpretation of data and preparation of the manuscript. T.S., T.H. assisted the data collection and its interpretation; A.K., P.P. participated in data interpretation; K.Y.I. assisted in the experiment and the preparation of the manuscript. K.I., Y.H., Y.F. contributed to prepare the Bio-LSI chip and partially assisted in the $\mathrm{O}_{2}$ measurement experiments. M.M., A.S. and R.K. contributed to prepare the Bio-LSI measurement system. T.M. revised the critically important content of the study. All authors approved the final version of the manuscript. 


\section{Additional Information}

Supplementary information accompanies this paper at https://doi.org/10.1038/s41598-019-48561-y.

Competing Interests: The authors declare no competing interests.

Publisher's note: Springer Nature remains neutral with regard to jurisdictional claims in published maps and institutional affiliations.

(c) (i) Open Access This article is licensed under a Creative Commons Attribution 4.0 International License, which permits use, sharing, adaptation, distribution and reproduction in any medium or format, as long as you give appropriate credit to the original author(s) and the source, provide a link to the Creative Commons license, and indicate if changes were made. The images or other third party material in this article are included in the article's Creative Commons license, unless indicated otherwise in a credit line to the material. If material is not included in the article's Creative Commons license and your intended use is not permitted by statutory regulation or exceeds the permitted use, you will need to obtain permission directly from the copyright holder. To view a copy of this license, visit http://creativecommons.org/licenses/by/4.0/.

(c) The Author(s) 2019 